\title{
Application of Wide Field Electromagnetic Method in the Geological Mapping of Benxi Ore Concentration Area
}

\author{
Bing Zheng, DiquanLi, MaojunTian \\ School of Geosciences and Info-Physics \\ Central South UniversityChangsha,China \\ zhengbing@csu.edu.cn
}

\begin{abstract}
In order to improve the comprehensive prospecting effect, wide field electromagnetic instrument system is used in Liaoning Benxi ore concentration areafor large depth and high precision geological mapping experimental work, 2D inversion imaging work is conducted based on nonlinear conjugate gradient method, the true resistivity characteristics of geo-electrical section of the ore concentration area is obtained, the ore-body shape is clearly delineated, the strata distribution, structure patterns and fracture characteristics of the area are basically identified. The results show that the wide field electromagnetic method can be effectively applied in the research of geological mapping in the ore concentration area.
\end{abstract}

Keywords—wide field electromagnetic method; geological mapping; strata; structure; fracture

\section{INTRODUCTION}

China's sustained rapid economic development and continuous improvement of people's living standards make the new higher demand for resources. China Geological Survey Bureau of land and resources put forward the macro deployment to strengthen the 'attack deep blind'in the eastern part of our country and to conduct the deep exploration work at 'the second ore belt' in the key metallogenic zone.

By 3D visualization of 3D geological model at the key perspective area, the spatial distribution characteristics of each epoch stratum and ore bearing strata in the area can be more intuitive. The formation isexposed completelyand distributedwidely in the Benxi ore concentration area, from Archean metamorphic supracrustal rocks to Cenozoic Quaternary are exposed, especially the classic development area of Neoproterozoic to Paleozoic. Geological structure is complex, tectonic trace throughout the region and mineral resources is rich, it is an ideal three-dimensional geological mappingarea. In order to assist three-dimensional geological mapping and improve integrated ore prospecting, the wide field electromagnetic method detection of the experimental work is conducted in Liaoning Benxi ore concentration area [1], through the study to identify the strata distribution, structure patterns and fracture characteristics and to provide wide field electromagnetic method exploration resultsfor three-dimensional geological mapping of ore concentration area.

\section{II.GEOLOGICAL AND GEOLOGICAL CHARACTERISTICS OF THE TEST AREA}

\section{A. Geological Characteristics}

Test area is located in the Liaoyang-Benxi depression of North China platform, Jiao Liao anteclise and Taiziriver-Hunjiangplatform and depression ${ }^{[2]}$,The dating strata are complete, mainly is sedimentary rock, followed by volcanic rock and metamorphic rock. The intrusive rocks are mainly distributed in the southwest of the research area, and the area is small. The geological structure already has the deep level ductile deformation, and also has the shallow level brittle deformation, the structural style is complex and diverse, there are the thrust and thrust system, the slip extension system and the sliding system. This area is an important part of the Liaodong-Jinan gold, lead and zinc polymetallicmetallogenic belt. The area is rich in mineral resources, mainly having iron, copper, lead and zinc, coal, etc.

The test area mainly experienced the complex structural evolution history from the ancient to the Cenozoic,different stages of evolutionformedthe different structural features and reflect different tectonic stages. According to the tectonic trace can roughly distinguish Anshan, Lvliang, Sibao-Hercynian cycle, Indosinian-Yanshanian and Himalayan five tectonic cycles.The detailed geological map is shown as Fig. 1. 


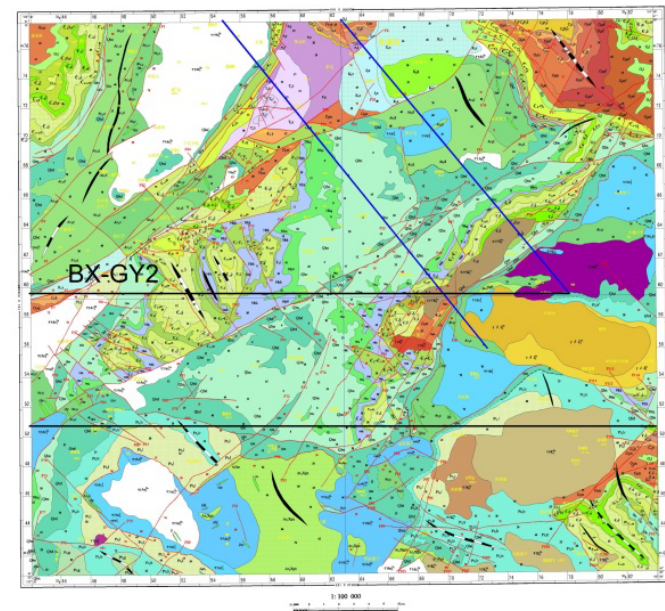

Fig.1. The geological map of Benxi ore concentration area

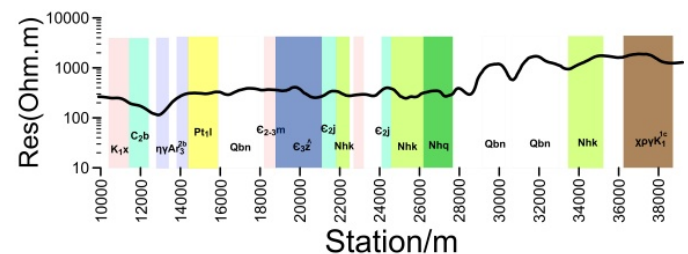

Fig.2. Thedebut statistical curve of strata resistivity curves of Benxi ore concentration area

\section{B. Geophysical Characteristics}

The physical properties research is mainly about two parts:study on the physical properties characteristics of strata and rocks, mainly on the study of the resistivitychange regulation.According to the layered model of electrical layers, whether it is two layers of structure or multi-layer structure, also regardless of the first layer is thick or thin, when effective frequency is high enough, the debut asymptote values are the values of the resistivity of the first layer. Combining the surface geological data, according to the curve of the debut and the stratigraphic unit, through the statistical method the formation model can be established, According to the statistics of the debut of wide field electromagnetic sounding the formation resistivity curve can be plotted, shown asFig. 2.

By comparing the resistivity characteristics of different layers in Fig.2, it can be seen that the resistivityof different strata have obviously difference, which provides an effective basis for wide area electromagnetic method detection.

\section{III.COMPREHENSIVE GEOLOGICAL INTERPRETATION}

Our own developed of "3D gravity magnetic electromagnetic integrated inversion imaging, and interpretation system "is used to process and inverse these data, we analyzed electrical characteristics of the strata in the area, combined with the electromagnetic inversion result, used geology and field outcrop materials, combined with the regional geological conditions, and from the aspects of depth, thickness and other aspects to conduct the comprehensive study, pointed out the mineral burial characteristics of the study area, gave the main extensional tectonic characteristics, effect of structural evolution on mineralization and control information of the area.

Next for line BX-GY2 as an example, contrasting identification ability of EH4 and wide field electromagnetic method for the iron ore and the geological structure and formation of the strata, the inversion and the geological interpretation results shown as Fig. 3.

Measuring line goes through the Dataigou iron ore, which is Asia's largest single iron ore - Benxi Dataigou iron ore, its prospective reserves will exceed 100 million tons, the

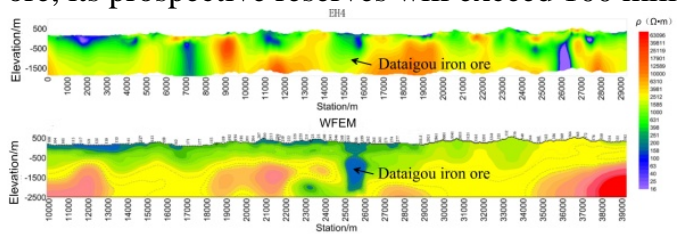

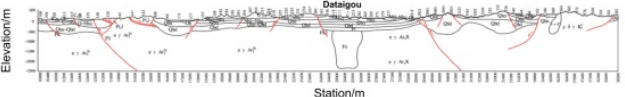

Fig.3. The results contrast and interpretation of line BX-GY2 orebody is $-900 \sim-1000 \mathrm{~m}$, the lowest elevation of controlling ore body is $-1770 \mathrm{~m}$ (up: the inversion results of of EH4,middle: the inversion results of the wide field electromagnetic method, down: the geological interpretation of widefield electromagnetic method)

Dataigou iron ore with burial depth, large reserves, steep dip angle, ore body extension of large, high technology content of the mining, the average grade of iron ore is estimated at about $32 \%$ of the average, part of the ore grade is reached $50 \%$. According to the design plan, the design of iron ore production capacity will reach 45 million tons, far exceeding the Kiruna iron ore mine with an annual output of 30 million tons of the world record. The Dataigou iron ore body is the general trend North West 315 degrees, with little tendency to northwest, the angle of 85 degrees \pm , the roof elevation of

In Fig. 3, EH4 inversion results are shown for "hanging noodles" like straight cliffy resistivity distribution, with the known geological data at odds (the stratigraphic occurrence is mainly horizontal, deep with rock mass), in addition, EH4 results show that only the surface of the Dataigou iron ore is low resistivity, at the deep does not show low resistivity anomaly, inconsistent with the Dataigou iron ore occurrence, EH4 did not reach expected geological target.

Seeing from the wide field electromagnetic method inversion imaging, the stratum of the research area is mainly horizontal from top to bottom with obvious layering, at the deep almost showed high resistance characteristics of rock mass. At the Dataigou iron ore, the low resistivity anomaly is obvious, which is a reflection of the deep extension of theDataigou iron ore. Combining inversion imaging and wide field electromagnetic method and known data, we inference that (1) The low resistivity anomaly in the west is related to the coal bearing strata of the Carboniferous System Benxi formation;(2)The top boundary of western basement granite shows undulating beneath the surface 800-1200 meters, the recessed areas ofSongshugou and Mijiabaozi two cover layers is caused by the impact of fracture;(3) East to 
theDataigou iron ore, cover layer is flat, the ups and downs is related to broad and gentle fold of Paleozoic strata surface under the surface;(4) TheDataigouiron ore is located 1600 meters below the surface of the earth, the low resistivity anomaly range is consistent with the ore body;(5) In the east of theDataigou iron ore, the top boundary of the granite is 1600 meters below the surface of the earth,the cover layer has a larger amplitude of the fold;(6) In the east end of profile, it is the detachment fault mylonite zone at the northwest of Heibeishan-Songshudixia metamorphic core complex, the shape of the rock mass and the contact interface between the cover layers reflect the existence of the detachment fault zone.

\section{IV.CONCLUSIONS AND RECOMMENDATIONS}

Wide field electromagnetic method basically identified the strata distribution, structure patterns and fracture characteristics of the area and can be effectively applied to [3] geological mapping.Because of the multiple solutions for geophysical inversion, it is suggested that the various geological and geophysical characteristics are considered in the use of this work.The wide field electromagnetic method exploration work is as four test lines for objective,the sites distance is dense,frequency sets is much,vertical resolution is high, mainly is two-dimensional section interpretation. But it is difficult to explain and predict from three-dimensional level. It is proposed to carry out large scale, large depth three-dimensional electromagnetic methodto deepen the understanding of the situation in the area.

\section{REFERENCES}

[1] HE Jishan, 2010, Wide field electromagnetic sounding methods and pseudo-random signal coding electrical method: Beijing: Higher Education Press.

[2] HongXiuwei, PangHongwei, Liu Xuewen.et al, 2010, Geological characteristics of the Dataigou iron deposit in Benxi, Liaoning Province[J].Geology in China,2010,37(5),1426-1433. 